\title{
DOSSIER
}

\author{
EL DINERO COMO \\ FENÓMENO SOCIAL \\ DE CONFIANZA
}


Se prohíbe su reproducción total o parcial por cualquier medio, incluido electrónico, sin permiso previo y por escrito de los editores. 


\section{PRESENTACIÓN: DINERO Y CONFIANZA}

${ }^{6} \mathrm{~N}$ adie ha visto todavía que los perros cambien de manera deliberada y equitativa un hueso por otro." ${ }^{1} \mathrm{El}$ intercambio es un fenómeno propiamente humano. La división del trabajo es posible porque los seres humanos pueden intercambiar lo que producen. La división del trabajo es la separación de tareas en cualquier sistema para que los participantes puedan especializarse, y en ella las ganancias económicas resultantes superan con creces los costos. Platón, ${ }^{2}$ con mucha agudeza, distinguió dos momentos en el proceso de satisfacer las necesidades humanas de alimento, vestido, habitación y demás. Un primer momento es analítico, cuando los agentes económicos se separan en actividades diversas (división del trabajo). El segundo momento es el sintético, el del mercado, en el que se intercambian los diversos productos del trabajo. Es así como para Adam Smith "recibimos la mayor parte de los servicios mutuos que necesitamos por convenio, trueque o compra, es esa misma inclinación a la permuta la causa originaria de la división del trabajo". 3

La utilización de dinero es una manera sumamente peculiar de adquirir cosas. No obstante, actualmente nos resulta tan natural la utilización del dinero que no nos maravillamos ante este hecho. Es difícil poner

${ }^{1}$ Adam Smith, Investigación sobre naturaleza y causas de la riqueza de las naciones, 1958, México-Buenos Aires, FCE, p. 16.

${ }^{2}$ Cfr. Platón, República, 369b ss.

${ }^{3}$ Smith, op. cit., p. 17. 
en duda la actualidad del tema del dinero cuando es un fenómeno en constante evolución, por lo que quizá despierte ahora en nosotros algo de curiosidad la reciente aparición de nuevos tipos de dinero o "monedas".

Desde hace tiempo es posible hacer pagos sin billetes físicos. Todos los bancos tienen portales en internet que pueden mover dinero electrónicamente de una cuenta a otra, incluso a través de las fronteras. Más recientemente, ha habido un rápido desarrollo de las plataformas de pago digital. En la India, en 2016, se trató de desmonetizar la rupia para reducir la corrupción. Se buscó reducir la dependencia del efectivo como moneda de curso legal. Crecieron Paytm, Samsumg y Mobikmik, entre otras plataformas. Se buscó una India "sin efectivo" o siquiera con "menos efectivo". En la misma línea, en Kenia, M-PESA, nombre del producto de telefonía móvil de Safaricom, proporciona servicios a los usuarios para realizar pagos con el teléfono móvil, enviar y recibir dinero entre usuarios, y retirar efectivo en cajeros, entre otros servicios dinerarios. ${ }^{4}$

También se han desarrollado las monedas locales, tales como los wir en Suiza y las libras brixton o totnes en el Reino Unido. En México, el tumin (que en totonaco significa "dinero") es una moneda local alternativa, que fue creada en 2010 en el municipio del Espinal, Veracruz, basada en el trueque y que ahora circula en varios estados del país.

Han prosperado también los bancos de tiempo, que tienen una moneda basada en el intercambio de tiempo de trabajo. ${ }^{5}$ Se intercambian servicios por servicios o favores por favores, la unidad de intercambio es el trabajo por hora. Solo se requieren individuos que estén dispuestos a pedir un préstamo en términos de tiempo de trabajo para que puedan liberarse de la obligación pagando en unidades monetarias o temporales (horas de trabajo), según el caso.

${ }^{4}$ Existen sistemas semejantes en diversos países escandinavos e incluso en China. En México hay pruebas piloto. Véase "Ya puedes enviar dinero desde WhatsApp", El Universal, 8 de abril de 2019, <https://www.eluniversal.com.mx/techbit/ya-puedes-enviar-dinero-desdewhatsapp>, consultado el 11 de abril de 2019.

${ }^{5}$ Véase $<$ https://timebanks.org/; http://www.bdtonline.org/>. 
Parecería que las criptomonedas son lo más novedoso que hay, pero no son lo último ni lo único. Entre las criptomonedas, los bitcoines ${ }^{6}$ son quizás las más famosas, pero ya hay muchos sitios electrónicos que ofrecen información diaria de las 100 principales criptomonedas por capitalización de mercado, ${ }^{7}$ mientras que otros brindan los datos relativos a la cotización diaria de cerca de dos mil. ${ }^{8}$

El dinero es un fenómeno humano, no cabe la menor duda. Desde sus orígenes, la existencia del dinero como medio de intercambio presupone la existencia de seres humanos y sus vínculos sociales. Y los medios de intercambio dependen cada día más de sus propiedades humanas, en particular de la confianza. En la actualidad, el dinero en su modalidad más sencilla, es decir, monedas y billetes, está basado principalmente en la confianza entre las partes que lo intercambian. Sin esta confianza el dinero dejaría de circular.

La moneda que representa un valor que intrínsecamente no lo tiene se llama "dinero fiduciario", término que proviene del latín $f i$ ducia, que significa "fe" o "confianza", y se refiere originalmente a la confianza que uno puede depositar en una o varias personas. Entre las cosas no cabe la confianza. El sistema financiero depende en su totalidad de la confianza que los seres humanos le puedan tener. Se tendrá más confianza en el dinero en la medida que cumpla con sus funciones de 1) unidad ideal, 2) medio de pago, 3) reserva de valor, y 4) patrón de pagos diferidos.

No es posible hacer aquí ni siquiera un brevísimo resumen de la evolución histórica del dinero; sin embargo, es un hecho que el dinero seguirá evolucionando, y al hacerlo, seguirá haciendo más justas las relaciones entre las personas.

Según Hegel, la aparición del dinero permitió que los individuos se relacionaran entre sí de manera más equitativa y que el valor del

${ }^{6} \mathrm{Al}$ respecto resulta interesante observar cómo algunas empresas dedicadas a operar activos virtuales quieren modificar las reglas secundarias para que el Banco de México (Banxico) les permita custodiar, transmitir e intercambiar criptomonedas. Véase Reforma, Negocios, 28 de marzo de 2019, p. 3.

${ }^{7}$ En $<$ https://coinmarketcap.com/es/>.

${ }^{8}$ En $<$ https://www.cryptocompare.com/coins/list/USD/19>. 
trabajo pudiera determinarse de manera más justa. Si imagináramos por un momento que desapareciera el dinero como medio de cambio, entonces los trabajos no tendrían ese algo que permita su intercambio. ¿Cómo se adquiriría la propiedad de lo que produzca el trabajo? ¿Cómo pagar por una cantidad de trabajo? Si no hay manera de pagar el trabajo ni su propiedad, entonces ¿cómo organizar justamente la sociedad? ¿Podría crear el mercado esta herramienta de justicia?

Es un hecho que el dinero hizo al mundo más justo y equitativo porque permitió que el intercambio entre los hombres se fundara en la libre voluntad y el arbitrio de las partes. ${ }^{9}$ Es en este contexto que hay que hacer una pregunta muy actual: ¿estos nuevos tipos de moneda permitirán un intercambio más justo y eficiente entre las personas?

La cuestión del dinero es donde se encuentran los más recientes debates y las discusiones más significativas sobre este elemento básico de la economía, donde la confianza tiene un papel fundamental.

Seguros de que las humanidades tienen mucho que decir sobre el dinero, la Universidad de Dallas (UD) y el Departamento Académico de Estudios Generales del ITAM planearon el Congreso 2017, que original-

12 mente estaba programado con la siguiente temática:

9 "Por medio del dinero [Geld] la justicia de la igualdad puede llevarse a cabo mucho mejor". Hegel, Principios de la filosofia del derecho o derecho natural y ciencia política, 2005, Madrid, Edhasa, trad. de Juan Luis Vermal, p. 449. 


\section{REUNIÓN UD-ITAM \\ CIUDAD DE MÉXICO, 2017 \\ Money as Social Phenomenon of Trust \\ EL DINERO COMO FENÓMENO SOCIAL DE CONFIANZA}

Viernes 29 de septiembre de 2017

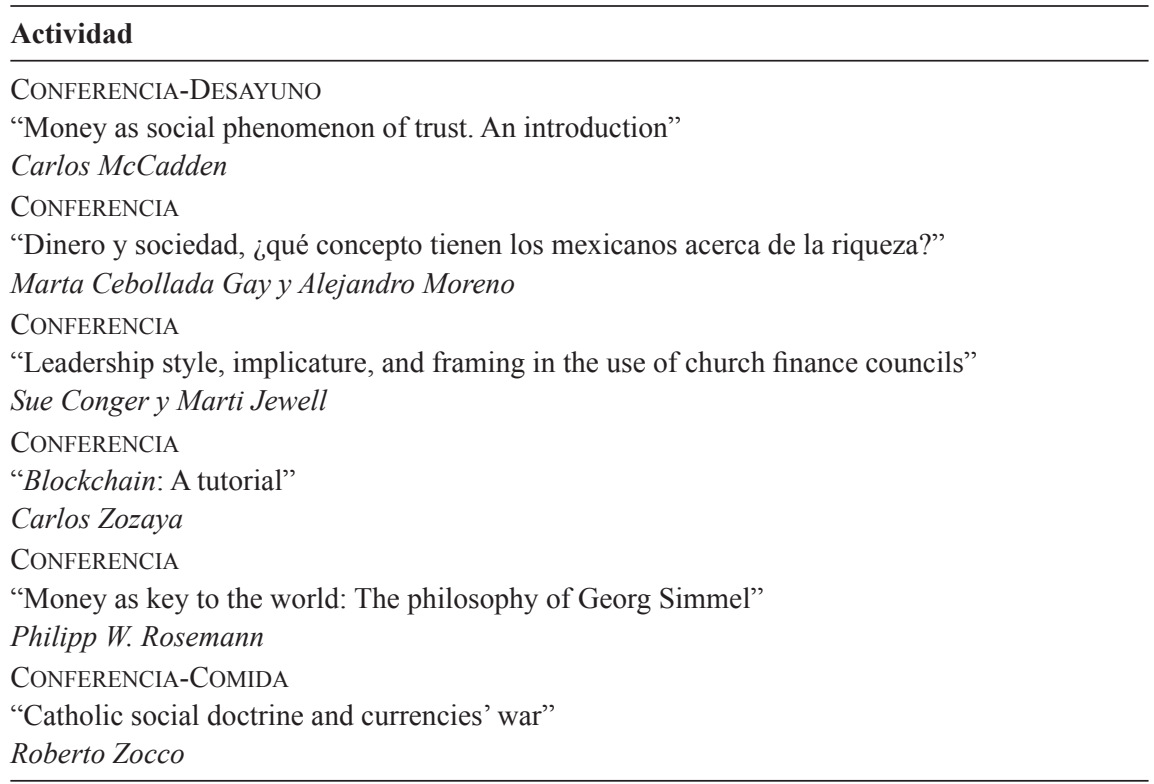

Sábado 30 de septiembre de 2017

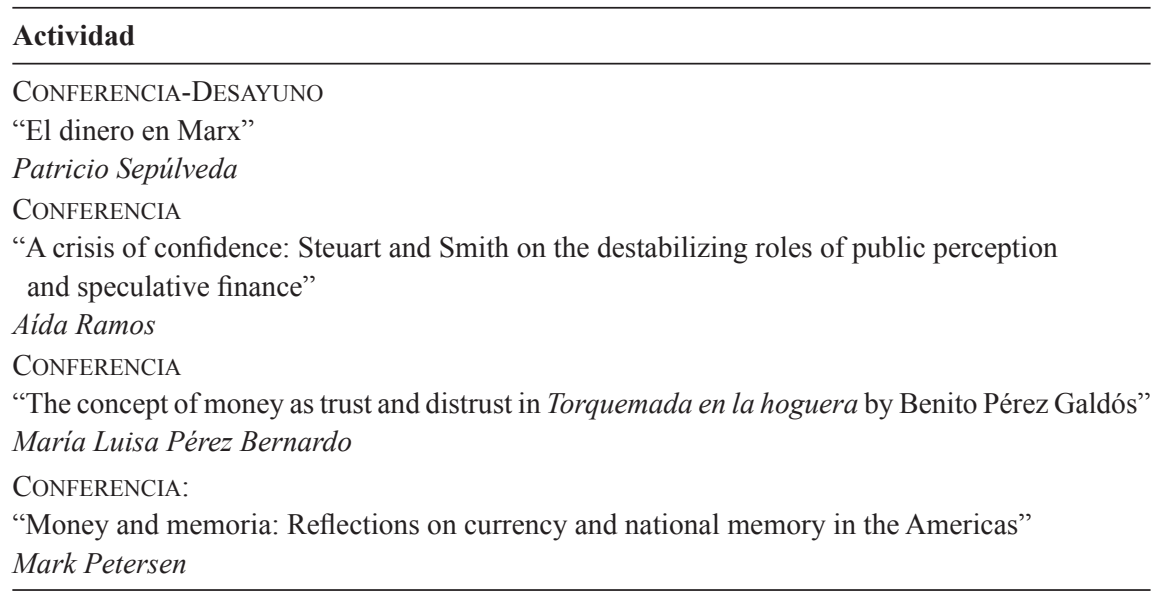


Justamente cuando este proyecto estaba generando mucha expectativa y alegría entre los profesores de ambas universidades, se produjo un evento terrible, el sismo de las 13:14 horas del martes 19 de septiembre de 2017, con sus subsecuentes réplicas, lo cual dejó una profunda herida social en nuestro México.

Ante esto hubo que repensar el encuentro. De inmediato recibí un correo electrónico del profesor Philipp W. Rosemann, coorganizador del grupo de Dallas, en el que se cuestionaba sobre la conveniencia de viajar a la Ciudad de México.

El encuentro entre universidades se canceló y se dispersaron las participaciones. Hubo algunas conferencias de profesores del ITAM y otras de profesores que viajaron desde la Universidad de Dallas.

En este número se publican los escritos que recogen o se refieren al tema del dinero como fenómeno social de confianza: Philipp W. Rosemann, "El dinero como clave del mundo: La filosofía de Georg Simmel"; Roberto Zocco, "La doctrina social de la Iglesia católica y la guerra de monedas"; María Luisa Pérez Bernardo, "El cuestionamiento del materialismo en Torquemada en la hoguera de Benito Pérez Galdós"; Carlos Zozaya, José Incera y Ana Lidia Franzoni, "Blockchain: Un tutorial” y Rafael González y Carlos McCadden, "Hegel, el dinero y la economía política".

Las reflexiones que se hacen en este número de Estudios sobre el dinero son una oportunidad para hablar de la humanización del ser humano y para repensar la dignidad de la persona humana en relación con la justicia, aspectos fundamentales de la misión del ITAM, la cual busca "contribuir a la formación integral de la persona y al desarrollo de una sociedad más libre, más justa y más próspera”.

Carlos J. McCAdDEn M. Jefe del Departamento Académico de Estudios Generales 